\title{
INTERACIONISMO NO CURSO DE PEDAGOGIA A DISTANCIA DA UFRGS: PRÁTICA OU RETÓRICA?
}

Amanda Ritter Stoffel - amanda_stoffel@yahoo.com.br Michele Doris Castro - micheledoriscastro@yahoo.com.br Monique Presser Cigolini - moniquecigolin@gmail.com Sérgio Roberto Kieling Franco - sergio.franco@ufrgs.br

\section{INTERACTIONISM IN UFRGS PEDAGOGY DISTANCE EDUCATION COURSE: PRACTICE OR RHETORIC?}

\begin{abstract}
This article attempts to identify and classify the presence of learning theories in interviews held with tutors of Distance Education Pedagogy Course at UFRGS (PEADUFRGS) when asked about their perceptions and practices while exercising their monitoring. The methodology adopted was semi-structured questionnaire. Then, analyses was performed by categorizing the responses. It was possible to observe the correspondence between theoretical proposal of the course, strongly inspired by interactionist bases, and their practice. This research makes it possible to relate the importance of developing a project which is actually implemented, aiming at success in the teaching-learning process.
\end{abstract}

Keywords: Pedagogy; interactionism; distance education; learning

Resumo: O presente artigo busca identificar e classificar a presença das teorias de aprendizagem existentes em entrevistas realizadas com tutores do curso de Pedagogia a Distância da UFRGS (PEAD-UFRGS) quando questionados sobre suas percepções e práticas no exercício de tutoria. Adotou-se, como metodologia, o uso de questionários semiestruturados. Posteriormente, foi realizada análise das respostas por categorização. Foi possível observar a correspondência entre a proposta teórica do curso, fortemente inspirada em bases interacionistas, e a execução de sua prática. A pesquisa possibilitou relacionar a importância da elaboração de um projeto que seja, realmente, posto em prática, visando o sucesso no processo de ensino-aprendizagem.

Palavras-chave: Pedagogia; interacionismo; educação a distância; aprendizagem. 


\section{INTRODUÇÃO}

No século XXI, a expansão das tecnologias de informação e comunicação abre espaço a questionamentos acerca de sua utilização e exige um reposicionamento daqueles que atuam em diversas áreas do conhecimento. Tanto no campo do ensino superior presencial como no do ensino a distância, há novas necessidades exigidas pela educação na formação dos indivíduos para a sociedade que desponta. Segundo Macedo e Grassi (2007, p.2), na educação, “a cada dia que passa são apresentadas variadas metodologias, paradigmas e recursos tecnológicos que contribuem no processo de ensino e aprendizagem do aluno”.

Envolver os professores nesse novo contexto é um grande desafio. Compreender quais as transformações que esta nova condição educacional promove na situação de aprendizagem dos alunos é um desafio ainda maior. Embora não tenhamos condições de antever os impactos decorrentes das novas tecnologias, existe a possibilidade de analisarmos continuadamente o curso de seu desenvolvimento. Por isso, indagar os atores envolvidos na sua utilização faz-se sumamente importante.

Esta pesquisa propôs-se a entrevistar os tutores do curso de Pedagogia na modalidade a distância da UFRGS a fim de questionar a sua compreensão enquanto agentes e testemunhas do processo de formação dos alunos. A escolha de tal curso deveu-se, entre outros motivos, ao fato de ser uma proposta que tem explícita sua opção teórica interacionista, como demonstram seus documentos, (NEVADO, 2007).

\section{DESENVOLVIMENTO}

Optou-se, como universo de pesquisa, o curso de Licenciatura em Pedagogia, modalidade a distância (PEAD) desenvolvido na Universidade Federal do Rio Grande do Sul. Esse curso é especificamente voltado à formação, em nível superior, de professores (das séries iniciais do Ensino Fundamental, de escolas públicas do Estado do Rio Grande do Sul). Foram enviados por correio eletrônico, no ano de 2009, questionários semi-estruturadas (perguntas abertas e fechadas) aos tutores do curso, bem como, elaborada a listagem e o estudo das ferramentas nele aplicadas. As entrevistas permitiram que os tutores expressassem sua 
interpretação da prática da tutoria. Foram enviados 40 questionários, dos quais retornaram 5 questionários devidamente preenchidos. Seguiu-se o método de categorização desenvolvido por Bardin (1979). Assim observou-se a perspectiva teórica subjacente às respostas apresentadas pelos tutores. Dessa forma, avaliou-se tal perspectiva conforme sua correspondência com a proposta teórica do curso (PEAD).

A perspectiva teórica observada no discurso dos tutores EAD foi avaliada a partir do quadro de categorias abaixo, este procura cobrir, esquematicamente, as principais classes teóricas e autores representativos com relação a teorias de ensino-aprendizagem. Sua elaboração foi consolidada após uma série de estudos realizados em projeto anterior o qual culminou na publicação de “Aprendizagem na Educação a Distância: Caminhos do Brasil” (FRANCO et alli, 2009).

\begin{tabular}{|c|c|c|c|c|c|}
\hline \multicolumn{2}{|r|}{ Empirismo } & \multicolumn{2}{|r|}{ Apriorismo } & \multicolumn{2}{|r|}{ Interacionismo } \\
\hline EB1 & \begin{tabular}{|l|} 
Aprendizagem \\
como mudança \\
de \\
comportamento \\
provocada por \\
elemento \\
externo \\
\end{tabular} & A1 A2 & $\begin{array}{l}\text { Aprendizagem: autogerada; } \\
\text { aprender por si próprio } \\
\text { ênfase na ideia da auto- } \\
\text { aprendizagem }\end{array}$ & I1 I2 & $\begin{array}{l}\text { Aprendizagem como } \\
\text { processo de construção a } \\
\text { partir de elementos do } \\
\text { sujeito e do meio. } \\
\text { Aprendizagem fruto das } \\
\text { interações (relações com o } \\
\text { meio). }\end{array}$ \\
\hline E1 & $\begin{array}{l}\text { Aprendizagem: } \\
\text { Captação de } \\
\text { conteúdo. }\end{array}$ & AG1 & $\begin{array}{l}\text { Desenvolvimento dá as } \\
\text { possibilidades para a } \\
\text { aprendizagem. }\end{array}$ & $\begin{array}{c}\text { IV1 } \\
\text { IPM1 } \\
\text { IP1 }\end{array}$ & $\begin{array}{l}\text { Aprendizagem } \\
\text { provocadora de } \\
\text { desenvolvimento. } \\
\text { Aprendizagem como } \\
\text { processo de auto- } \\
\text { regulação. Aprendizagem } \\
\text { relacionada aos processos } \\
\text { de assimilação e } \\
\text { acomodação. }\end{array}$ \\
\hline EBC & \begin{tabular}{|l} 
Ênfase no \\
planejamento do \\
ensino (ensino \\
causa \\
aprendizagem)
\end{tabular} & $\begin{array}{l}\text { A3 A4 } \\
\text { AH2 } \\
\text { AH1 }\end{array}$ & \begin{tabular}{|l|} 
Autonomia como sinônimo \\
de fazer sozinho. Ênfase \\
absoluta na atuação do aluno. \\
O aluno (indivíduo) dita os \\
passos do processo. \\
Motivação intrínseca como \\
elemento chave para a \\
aprendizagem.
\end{tabular} & $\begin{array}{l}\text { IVM1 } \\
\text { IV2 } \\
\text { IPM2 }\end{array}$ & $\begin{array}{l}\text { Aprender com o outro } \\
\text { (relação social). Ênfase na } \\
\text { relação professor/aluno, } \\
\text { tutor/aluno, aluno/aluno. } \\
\text { Aprendizagem como } \\
\text { processo e não resultado. }\end{array}$ \\
\hline E2 & $\begin{array}{l}\text { Material } \\
\text { instrucional } \\
\text { como elemento } \\
\text { central para } \\
\text { garantir } \\
\text { aprendizagem. }\end{array}$ & AH4 & $\begin{array}{l}\text { Material instrucional como } \\
\text { incentivador e não } \\
\text { necessariamente fonte do } \\
\text { conhecimento. }\end{array}$ & I3 & $\begin{array}{l}\text { Material instrucional } \\
\text { como um dos } \\
\text { provocadores do processo } \\
\text { (elemento de } \\
\text { desequilíbrio). }\end{array}$ \\
\hline \multicolumn{6}{|c|}{ Legenda: } \\
\hline \multicolumn{3}{|c|}{ A: Apriorismo } & \multicolumn{2}{|c|}{ I: Interacionismo } & \\
\hline & B: Behaviorismo & & M: Ma & & \\
\hline
\end{tabular}




\begin{tabular}{|l|l|}
\hline C: Cognitivismo & PI: Platão \\
\hline E: Empirismo & P: Piaget \\
\hline G: Gestalt & V: Vygotski \\
\hline H: Humanismo & \\
\hline
\end{tabular}

Quadro 1: Categorias de Análise

Fonte: FRANCO et alii. Aprendizagem na Educação a Distância: Caminhos do Brasil. Disponível em: <http://www.pucpr.br/eventos/educere/educere2009/anais/pdf/2096_1042.pdf>

\subsection{Resultados e Discussão}

Os entrevistados partiram de sua vivência prática para responder às perguntas. Através das respostas, pretendeu-se verificar indícios da concretização do projeto pedagógico do curso, o qual, como foi assinalado anteriormente, parte de bases fortemente interacionistas.

A análise das respostas revelou que as ferramentas mais citadas como boas fontes de auxílio para o desenvolvimento da aprendizagem dos estudantes foram, respectivamente: blogs, fóruns e correio eletrônico. As respostas fixaram-se em ferramentas cujo funcionamento está centrado, predominantemente, na interação e na construção conjunta pelos agentes envolvidos no processo educacional (tutores, professores e alunos). Com base nessas respostas infere-se razoabilidade entre a proposta teórica do curso e das ferramentas adotadas.

No que tange à interação entre alunos e tutores foram mais lembradas as aulas presenciais e resolução de problemas. Como justificativa para as respostas, os tutores, por várias vezes, mencionaram que a aula presencial garante a possibilidade de manutenção dos vínculos entre alunos e professores. Percebe-se nessas respostas a permanência da ideia de que a distância física afasta os seres humanos, assim, os encontros presenciais garantiriam a permanência deste vínculo, supostamente diminuído pela modalidade adotada pelo curso.

Quanto aos momentos de resolução de desafios (problemas), estes seriam as oportunidades dos tutores mostrarem a sua utilidade enquanto agentes facilitadores do processo de ensino/aprendizagem nos cursos a distância, pois, ao tentarem superar as dificuldades dos exercícios, os alunos necessitariam recorrer à ajuda dos tutores e assim formar-se-ia a percepção simbólica da importância dos tutores no pensamento dos alunos.

Os tutores poderiam citar até três motivos fundamentais, de escolha pessoal, para justificar o que, no seu entendimento, promoveria mudança de atitude nos alunos 
tutorados. Além das opções oferecidas (atividades listadas), podiam acrescentar ao rol novas que julgassem efetivas para promoção desta mudança. Na análise desta questão, percebe-se grande recorrência a três argumentos centrais: busca e solução de problemas, encontros presenciais e troca de informações. Segundo os tutores, os alunos, quando colocados frente a frente às novas dificuldades, no caso os exercícios propostos, sentem necessidade de buscar novas informações a fim de solucionar os problemas.

Desta ação, resultaria aumento da criatividade e familiarização com as novas tecnologias e ferramentas advindas com a educação a distância. Os alunos, ao serem desafiados procurariam novos conhecimentos o que levaria a uma rearticulação permanente das suas aprendizagens anteriores, bem como aos sentidos atribuídos a estas. Logo, desenvolveriam uma visão de aprendizagem alicerçada na responsabilidade e no comprometimento pessoal ao longo do curso. Tal fato fica evidenciado pelas assertivas de dois dos tutores entrevistados, apresentadas abaixo:

"resolver problemas de diferentes tipos relacionados às atividades discentes favorece o desenvolvimento da autonomia e iniciativa, uma das grandes aprendizagens num curso EAD"

"Os alunos iniciaram o curso esperando receber informações e ao longo dos semestres foram desafiados a serem autônomos na construção de suas aprendizagens, na resolução de problemas e busca de informações".

Outro aspecto interessante desta questão remete à importância dada pelos tutores aos encontros presenciais, estes que aqui aparecendo enquanto momentos de reflexão, legitimação e reafirmação dos vínculos necessários à formação dos alunos. Aspecto este expresso nas respostas de mais dois tutores entrevistados:

\footnotetext{
"A aula presencial deve ser o momento de encontro entre os pares (sujeitos envolvidos no curso) para que o Curso seja legitimado. Esta participação também promove uma mudança de atitude no aluno".

“... é o momento de nos conhecermos. O contato pessoal é importante porque cria uma familiaridade”.
}

Embora encontremos nas respostas alusão à educação a distância enquanto ampliadora de laços, ainda percebe-se fortemente menção à necessidade dos encontros presenciais no reconhecimento do curso entre os agentes envolvidos. Mesmo se tratando de um curso a distância, no imaginário simbólico dos entrevistados a proximidade física 
é tida enquanto fundamental para que a educação aconteça. Possivelmente, sob as respostas, a ideia de que a educação a distância ainda é uma forma nova de aprender e ensinar.

O terceiro aspecto que se apresenta marcante nas repostas, trocas de informações, chama novamente atenção para a necessidade de familiarização com as “novas tecnologias”, como sugerem as respostas abaixo:

\footnotetext{
"As alunas tem demonstrado bastante domínio tecnológico e utilizam isso a seu favor na apresentação e realização de trabalhos”.

"as trocas são a chave para interação".
}

Estas trocas abririam caminho para as novas aprendizagens. Chama-se atenção aos três aspectos tidos como fundamentais para o sucesso da educação a distância: busca e solução de problemas, encontros presenciais e troca de informações. Ponderase aqui a alusão à ideia de educação a distância enquanto forma, a ser recheada pelos seus ingredientes vitais: vínculo/contato, exercício e comunicação.

Outro ponto de nossa investigação assenta-se na verificação de quais os indícios citados pelos tutores apontavam para mudanças de comportamento dos alunos ao longo do curso.

Dentre os indícios abordados, mostraram-se mais presentes: ganhos de qualidade nos trabalhos desenvolvidos e, principalmente, a participação nas atividades propostas e autonomia na formulação de idéias.

Segundo os tutores, alguns alunos, ao entrarem no curso apresentariam dificuldades iniciais de compreensão da lógica de seu funcionamento e de operacionalização das tecnologias e ferramentas utilizadas. Ao longo da graduação, porém, o crescimento da qualidade dos trabalhos apresentados e a maior participação dos alunos nas atividades sugeridas apontariam para uma mudança de atitude perante o curso. Abaixo, o depoimento de uma tutora entrevistada que comenta sobre as emoções de alunos no início do curso exemplifica o acima exposto:

\footnotetext{
"Temos casos de alunos que apresentaram dificuldades enormes em alguns workshops, como choro por ansiedade e medo e dificuldade cognitiva de articular conhecimentos".
}

Continua relatando a tutora ao escrever sobre o desenvolvimento destes mesmos alunos: 
"Depois de alguns semestres, contudo, revelaram aprendizagens significativas sobre autoria, individualidade, autoconfiança. São casos de superação, no aspecto emocional relacionado ao momento de se expor à avaliação, e também casos de desenvolvimento de habilidades cognitivas de reflexão, compreensão e articulação de conceitos”.

\subsection{Avaliação das Teorias Educacionais}

A respostas fornecidas pelos tutores do PEAD permitiram uma análise acerca de possíveis concepções teóricas educacionais presentes na prática do curso. Foi possível perceber claramente a preponderância da classe teórica Interacionista, representada por autores como Vigotsky, Maturana e Piaget.

Dentre as categorias utilizadas para análise houve o predomínio da categoria IVM1 (quadro 1), que traz elementos presentes nas teorias de Vigotsky e Maturana. É definida como “Aprender com o outro”, e caracterizada pela aprendizagem a partir das relações sociais. A presença dessa categoria demonstra a importância dada pelos tutores às trocas possíveis a partir da interação entre os sujeitos, conforme exemplificam os trechos extraídos dos questionários:

"Possibilita que ideias sejam trocadas e motiva a interação entre os sujeitos”.

“O contato pessoal é importante porque cria uma familiaridade”.

A importância das trocas no ensino não presencial é focada pelos tutores a partir da relação com o meio, definida na categoria e categoria I1 “Aprendizagem como processo de construção a partir de elementos do sujeito e do meio”. A interação entre o tutor e o aluno surge, no discurso dos tutores, a partir da presença da categoria IV2, definida como a “Ênfase na relação professor/aluno, tutor/aluno, aluno/aluno”.

A aprendizagem como processo e não resultado, categoria IPM2, foi encontrada no discurso dos tutores:

\footnotetext{
"Precisam reelaborar seus conhecimentos articulando não apenas aprendizagens, mas os sentidos das aprendizagens, desenvolvendo uma visão de processo e de responsabilidade pela própria caminhada”.
}

A classe apriorista divergente a proposta pedagógica do curso foi detectada essencialmente quando relacionado ao conceito de autonomia, conforme trechos: 
"Resolver problemas de diferentes tipos relacionados às atividades discentes favorece o desenvolvimento da autonomia e iniciativa, uma das grandes aprendizagens num curso EAD".

"O Aluno de Educação a Distância deve ter esta característica (autonomia) de buscar informações'.

Em tais casos a autonomia é vista como sinônimo de fazer sozinho, caracterizada pela categoria A3. O apriorismo manifestou-se ainda na presença da categoria A2, com ênfase na idéia da auto-aprendizagem, e no aprender por si próprio:

“...longo dos semestres foram desafiados a serem autônomos na construção de suas aprendizagens, na resolução de problemas".

Como verificado em pesquisa anterior (Franco et alii, 2009), é comum a coexistência da concepção interacionista com a apriorista, decorrente, segundo nossa hipótese, do processo histórico de incorporação das teses interacionistas no Brasil. De qualquer forma, cabe destacar que a presença de categorias apriorista mostrou-se minoritária.

\section{CONCLUSÃO}

Com os estudos verificou-se forte presença de três argumentos que parecem ter força central nas reflexões dos tutores quando pensam na proposta de educação a distância desenvolvida no Curso de Pedagogia a distância da UFRGS: necessidade da manutenção de vínculos, trocas de informações e ganhos de autonomia a partir dos exercícios desenvolvidos.

As respostas mostram a correspondência entre a proposta teórica do curso, fortemente inspirada em bases interacionistas, e a execução de sua prática.

Repete-se a importância da contínua reflexão e estudo das estruturas sobre as quais estão alicerçadas as bases dos diferentes projetos de educação a distância desenvolvidos no país. Não só a correspondência entre o projeto teórico e a prática deve ser verificada, mas também quais e como são aplicadas as ferramentas desenvolvidas nesses cursos. A elaboração de um projeto que seja realmente posto em prática reflete um funcionamento coerente do curso, o que foi verificado no caso estudado. Cabe, pois, o questionamento final: será isso recorrente na maioria dos cursos a distância (e também dos presenciais) em nossas universidades? 


\section{REFERENCIAS}

BARDIN, Laurence. Análise de conteúdo. Lisboa: 70, 1979.

BECKER, Fernando. A epistemologia do professor: o cotidiano da escola. 7. ed. Petrópolis: Vozes, 1999.

FRANCO et alii. Aprendizagem na Educação a Distância: Caminhos do Brasil. Disponível em: <http://www.pucpr.br/eventos/educere/educere2009/anais/pdf/2096_1042.pdf>

FRANCO, Sérgio Roberto Kieling (org.). Educação a distância na Universidade Federal do Rio Grande do Sul. Porto Alegre: UFRGS, 2004.

FRANCO, Sérgio Roberto Kieling (org.). Informática na educação: estudos interdisciplinares. Porto Alegre: UFRGS, 2004.

GUIA DO ALUNO. Disponível em: $<$ http://www.pead.faced.ufrgs.br/sites/publico/pead-informacoes/guia_do_aluno.pdf $>$

GUIA DO PROFESSOR. Disponível em: http://www.pead.faced.ufrgs.br/sites/publico/pead-informacoes/guia_do_professor.pdf>

MACEDO e GRASSI. Formação de Professores em Informática Educativa na modalidade a distância: um relato de experiência do SENAC/RS. Porto Alegre: Cinted/UFRGS, 2006.

MATURANA, Humberto e Varela, Francisco.(2001). A árvore do conhecimento. As bases biológicas da compreensão humana. São Paulo: Palas Athena.

LÉVY, Pierre. (1998). As tecnologias da inteligência. São Paulo: ED34.

OLIVEIRA, Marta Kohl de. Vygotsky: aprendizado e desenvolvimento: um processo sóciohistórico. 3. ed. São Paulo: Scipione, 1995.

PETERS, Otto. A educação a distância em transição. São Leopoldo: UNISINOS, 2001a.

PIAGET, Jean. (1970) A epistemologia genética. São Paulo: Abril Cultural, 1978. pp. 1-64. (Col. Os Pensadores.)

ROGERS, Carl R. Tornar-se pessoa. 5. ed. São Paulo: Martins Fontes, 1997.

VYGOTSKI, Liev Semiónovich. Pensamiento y lenguaje. In VYGOTSKI, Liev Semiónovich. Obras escogidas. Tomo II. Madrid: MEC/Visor, 1993. 
ZULIAN, Margaret Simone. Redes virtuais: formação de professores. Porto Alegre: Imprensa Livre, 2003. 